\title{
A legitimidade democrática da Justiça constitucional
}

https://doi.org/10.21814/uminho.ed.30.22

\author{
Maria Hylma Alcaraz Salgado \\ Professora interina de Direito Constitucional da \\ Universidade de Vigo, Espanha
}

\section{Introdução}

Os Estados que integram a Comunidade Lusófona instituem diferentes modelos de Justiça Constitucional. Independentemente da adoção de um sistema difuso ou concentrado de controle da constitucionalidade das leis, o certo é que todas as Cortes Constitucionais têm atribuída a difícil tarefa de exercer o controle da constitucionalidade das leis.

O controle da constitucionalidade das leis tem como efeito declarar a congruência ou a incompatibilidade de um texto legal com as disposições da Constituição. A Corte Constitucional ao pronunciar-se sobre a inconstitucionalidade de uma lei declara sua nulidade, atuando como legislador negativo ${ }^{1}$. A atuação dos Tribunais Constitucionais, neste sentido, é alvo de críticas; em especial, questiona-se a legitimidade das referidas Cortes para decidir sobre a validade ou invalidade de uma lei, uma vez que a missão dos órgãos jurisdicionais não é legislar, mas aplicar o Direito emanado das diversas fontes democraticamente instituídas.

A discussão sobre a legitimidade democrática da Justiça Constitucional não é uma novidade, mas uma questão permanentemente aberta às reflexões das teorias políticas e jurídicas. Pode-se dizer que é uma questão aporética, e como tal, permite uma ampliação cognoscitiva do problema, o que justifica sua relevância.

1 KELSEN, H. La garantia jurisdicional de la Constitución (la justicia constitucional). [Em linha]. (2011) $n^{\circ} 15$ [consultado em 2020-03-15], pp. 249-300. Disponível na World Wide Web: https://www.google. com/url?sa=t\&rct=j\&q=\&esrc=s\&source=web \&cd=\&ved=2ahUKEwj-25D6U_xAhXOy4UKHYZCCOYQFjA BegQICxAD\&url=https\%3A\%2F\%2Fdialnet.unirioja.es\%2Fdescarga\%2Farticulo\%2F3764308.pdf\&usg= AOvVaw2WZE7ejWqZo7vZdrG5DbOO. 


\section{A legitimidade democrática da justiça constitucional}

\subsection{Breve referência à evolução do controle de constitucionalidade das leis}

A debatida questão sobre a legitimidade democrática da justiça constitucional está vinculada à evolução do sistema de controle da constitucionalidade das leis. Com a consagração do princípio de supremacia da Constituição foi necessário introduzir um sistema de garantias para resguardar seus mandados, como também determinar que órgão deveria responsabilizar-se de controlar sua aplicação. A separação de poderes foi a fórmula estabelecida para garantir a supremacia da Constituição. Em 1789, a Declaração dos Direitos do Homem e do Cidadão, em seu artigo 16, já preconizava: "A sociedade em que não esteja assegurada a garantia dos direitos nem estabelecida a separação dos poderes não tem Constituição". No alvorecer do constitucionalismo, Sieyès defendeu a ideia de incorporar garantias judiciais para resguardar a supremacia da Constituição, mediante a organização de um tribunal constitucional. Em território americano, Alexander Hamilton, no mesmo sentido, propôs outorgar aos juízes a tarefa de interpretar a Constituição e manter sua supremacia ${ }^{2}$. Entretanto, estas ideais não foram recebidas com entusiasmo, ao contrário, deram início a uma polarização entre os defensores de uma justiça constitucional e os objetores do controle judicial da Constituição.

Nos Estados Unidos de América a tensão política produzida pelo sistema de freios e contrapesos dos três poderes constituídos permitiu que a Corte Suprema americana consolidasse a sua posição como guardiã da Constituição por intermédio da sentença proferida em 1803 pelo juiz John Marshall no famoso caso Madison versus Marbury. Mas, no continente europeu o reconhecimento da potestade judicial no controle constitucional só ocorreu no século seguinte. Apesar das vozes contrárias, a ideia defendida por Kelsen ${ }^{3}$ de criar um tribunal especializado para resguardar a supremacia da Constituição acabou prosperando na Europa. Estes dois caminhos foram determinantes para estabelecer os principais modelos de justiça constitucional que conhecemos na atualidade: o modelo difuso, fruto da experiência americana, e o modelo concentrado, desenvolvido pelos europeus.

\subsection{A problemática questão da legitimidade da justiça constitucional}

O controle sobre a adequação das leis aos preceitos constitucionais realizado por um tribunal constitui o cerne da questão relativa à legitimidade democrática da

2 TARCK, Christian. La legitimación de la justicia constitucional y el principio democrático. [Em linha].(2003) $n^{\circ} 7$ [consultado em 2021-04-19], pp. 479-493. Disponível na World Wide Web: https://www.google.com/ url?sa=t \&rct=j\&q=\&esrc=s\&source=web \&cd=\&cad=rja \&uact=8\&ved=2ahUKEwjF-8mclZ_xAhVNOhoK HcEID2oQFjAEegQICxAE\&url=https\%3A\%2F\%2Fwww.cijc.org\%2Fes\%2Fconferencias\%2F2014-SantoD omingo\%2FDocumentos\%2520CIJC\%2FConferencia\%2520de\%2520la\%2520Presidenta\%2520del\%252 OTribunal\%2520Constitucional\%2520de\%2520Chile.pdf\&usg=AOvVaw24GgBVK2Vsn9UCTOeRzlyO.

3 KELSEN, H. Obra citada. 
justiça constitucional. Por um lado, estão os defensores da justiça constitucional que propugnam o necessário controle sobre a aplicação dos mandados constitucionais por um órgão independente, com o fim de garantir a supremacia da Constituição. De outro, estão os que se opõem ao controle jurisdicional da Constituição alegando a carência de legitimidade democrática dos juízes para invalidar leis aprovadas por um Parlamento.

A legitimidade democrática, dentro do discurso político contemporâneo, está associada ao reconhecimento da validade das instituições política e jurídicas, fruto da participação da cidadania na criação das leis e na gestão dos interesses coletivos mediante um sistema representativo que encontra seu fundamento no sufrágio universal. Deste modo, a democracia é concebida como representação popular ou participação cidadã na tomada de decisões fundamentais que se realiza por intermédio do voto. Esta representação que se origina na vontade popular é a razão de ser da legitimidade das instituições democráticas. Neste sentido, a regra da maioria é uma importante medida para expressar um certo consenso social.

No entanto, o princípio democrático não se manifesta por igual entre os poderes constituídos. A regra da maioria, exigência para a legitimação do governo e dos atos do Parlamento, não está presente na esfera judicial, porque os tribunais não contam com a representação popular em sua composição e, tão pouco, em seus procedimentos decisórios. Por esta razão, os objetores da justiça constitucional consideram que os tribunais não possuem legitimidade democrática para anular as leis aprovadas por assembleias eleitas pelo povo ${ }^{4}$. Esta posição contramaioritária dos tribunais produz um déficit democrático ${ }^{5}$, que constitui o principal alvo das críticas sobre a legitimidade do modelo de controle de constitucionalidade das leis.

\subsection{Argumentos em defesa da legitimidade da justiça constitucional}

As teses que negam existir uma tensão entre a justiça constitucional e a democracia se fundamentam em distintos argumentos. Fazendo uso do mapeamento feito por Víctor Ferreres Comella ${ }^{6}$ de referidos argumentos é possível agrupá-los em três principais orientações: a) as teses que pretendem dissolver esta tensão mediante a consolidação de uma concepção substantiva da democracia; b) as teorias que defendem o maior grau de legitimidade popular da Constituição frente às menores credenciais democráticas das leis; $c$ ) as teses que advogam pelas vantagens instrumentais do processo judicial no controle da constitucionalidade das leis.

A democracia substantiva é uma proposta conceitual que pretende ampliar a noção desenvolvida pela denominada "democracia procedimental", entendida, esta

\footnotetext{
4 FERRERES COMELLA, Víctor (Dir.). Una defensa del modelo europeo de control de constitucionalidad. $1^{\text {a }}$ edición. Madrid: Marcial Pons, 2011, p. 139. ISBN 978-84-9768-845-1.

5 Idem, Ibidem, p. 140.

6 Idem, pp. 141-148.
} 
última, como método para obtenção de consenso mediante a regra da maioria. A concepção substantiva alega que a democracia não reside somente no procedimento eleitoral e decisório; exige, também, a observância de certos valores sociais, a construção de uma ordem política e social justa, a garantia dos direitos fundamentais e o desenvolvimento de uma concepção compartilhada do bem comum ${ }^{7}$. Os defensores da concepção substantiva da democracia ${ }^{8}$ consideram que o controle da constitucionalidade das leis está plenamente justificado porque a adequada aplicação das leis dentro dos parâmetros constitucionais é uma garantia da própria democracia. Quando os juízes anulam leis contrárias aos preceitos da Constituição estão protegendo direitos e resguardando os valores da comunidade, o que thes confere um importante papel para a consolidação dos princípios democráticos.

O segundo bloco teórico apoia seus argumentos no princípio de supremacia da Constituição. Neste sentido, o controle da constitucionalidade das leis realizado pelos tribunais é necessário para preservar os princípios estabelecidos pelo povo nos momentos extraordinários de deliberação democrática (os momentos constitucionais), diante da erosão que podem sofrer pelas ações de seus representantes no curso da política ordinária9. Deste modo, os mandados constitucionais devem ser respeitados pelo legislador ordinário para preservar a autêntica vontade democrática. E, quando os legisladores não observam os preceitos constitucionais, é preciso contar com uma via institucional que proteja os valores democráticos resguardados pela Constituição. Neste contexto, o controle de constitucionalidade das leis se configura como instrumento legítimo para a proteção dos cidadãos diante de decisões políticas que possam afetar a ordem constitucional estabelecida.

A terceira orientação teórica considera a importância que assume o processo judicial na proteção dos direitos e dos interesses individuais, nem sempre representados pela regra da maioria. Dentro desta vertente, Víctor Ferreres Comella ressalta a tese desenvolvida por Lawrence Sager ${ }^{10}$, para quem a democracia deve ser considerada a partir de duas óticas distintas: a perspectiva eleitoral, na qual os cidadãos participam na escolha de seus representantes em igualdade de condições por meio do voto, e a dimensão deliberativa que se manifesta por intermédio das decisões tomadas pelas autoridades, as quais devem privilegiar os direitos e interesses dos indivíduos. Considerando estas perspectivas, a dimensão eleitoral da democracia tem sua melhor expressão na atividade legislativa, enquanto que a democracia deliberativa se desenvolve por meio dos tribunais.

7 QUIROGA, Hugo. ¿Democracia procedimental o democracia sustantiva? La opción por un modelo de integración. [Em linha]. (2000) n³ 3, vol. VI. [Consultado em 2021-05-09], pp. 361-374. Disponível na World Wide Web: https://dialnet.unirioja.es/servlet/articulo?codigo=5848857.

8 A concepção substantiva da democracia se desenvolve por intermédio de várias correntes teóricas que buscam assegurar os valores e os direitos fundamentais dos membros de uma sociedade como conteúdos essenciais do ideal democrático. Em virtude da amplitude de seu objeto de estudo, esta teoria consta com inúmeros representantes, tanto clássicos quanto contemporâneos.

9 FERRERES COMELLA, Víctor. Obra citada, p. 145.

10 Apud Ferreres Comella, Víctor. Obra citada, pp. 146-148. 
Os argumentos em defesa do controle de constitucionalidade das leis, anteriormente apresentados, têm em comum os seguintes aspectos: a necessidade de redefinir a democracia e a ampliação das vias de legitimação democrática das instituições. Em sua significação mais extensa, a democracia é entendida formalmente, ou seja, como um procedimento que permite à cidadania expressar a vontade popular pelo voto. Esta via de legitimação direta, resultante do exercício eleitoral, é a que está arraigada como modelo democrático. Neste sentido, a fonte de legitimidade das instituições criadas para proteger os valores democráticos são indiretas, como ocorre com os tribunais. Entretanto, os conceitos de democracia e legitimidade não são unívocos, o que permite localizar em seus núcleos significativos elementos intrínsecos a referidos fenômenos políticos que se referem a outras dimensões não procedimentais. Por esta razão, a harmonização dos conceitos de democracia procedimental e democracia substantiva e a compreensão das diferentes formas de legitimação dos poderes constituídos são possíveis soluções para equilibrar o acusado déficit democrático da justiça constitucional.

\section{O controle da constitucionalidade das leis}

Os sistemas desenvolvidos para controlar a adequação das leis aos comandos constitucionais respondem à evolução do Estado de Direito. A implantação do modelo de Estado liberal se fundamenta no princípio da legalidade, cujo núcleo ontológico contem os elementos que plasmam os ideais democráticos. Na tradição jurídica, a lei é a única fonte legítima para reconhecer direitos e impor limites à atuação dos atores políticos e sociais, por ser a máxima expressão da vontade popular. Entretanto, a transformação do Estado de Direito em Estado constitucional de Direito modifica o status da Constituição, que deixa de ser um documento político para adquirir valor de norma jurídica, com as seguintes consequências: a) a Constituição passa a ser o parâmetro e a fonte de validade da lei e do resto do Ordenamento Jurídico; b) faz-se necessário criar mecanismos para garantir a supremacia da Constituição, capazes de neutralizar as normas contrárias aos seus mandados ${ }^{11}$.

A consagração do princípio de supremacia da Constituição e o reconhecimento de seu valor normativo conforma um novo eido, que incide (entre outras) sobre a função judicial. A atividade judicial, que no Estado liberal se limita a dizer o Direito criado pelo Legislativo, incorpora agora a tarefa de aplicar leis válidas, isto é, compatíveis com os preceitos constitucionais. 0 exame da compatibilidade da lei com a Constituição feito pelos juízes no momento da aplicação da lei ao caso concreto, além de sua função garantista, consolida a posição institucional do Judiciário, a quem compete atualizar o pré-compromisso constitucional mesmo tendo que neutralizar decisões de outros poderes públicos ou privados. ${ }^{12}$ Essa nova realidade conduz ao questionamento sobre a legitimidade democrática das decisões judiciais que anulam os atos

11 LOPERA MESA, Gloria Patricia. La problemática legitimidad de la justicia constitucional. "Anuario Iberoamericano de justicia constitucional”. [Em linha]. (2001) n 5 [Consultado em 2021-04-25], pp. 227-256. Disponível na World Wide Web: https://dialnet.unirioja.es/servlet/articulo?codigo=1976017.

12 Idem, Ibidem, p. 247. 
legislativos, ainda que tais decisões estejam fundadas na necessária manutenção da supremacia da Constituição.

É certo que os juízes encarregados de exercer o controle da constitucionalidade das leis não ostentam a legitimidade originária, porque não são eleitos pelo voto popular e suas decisões não resultam de deliberações públicas. Entretanto, as normas que orientam o desenvolvimento do processo judicial exigem que os juízes sejam imparciais e independentes, que motivem suas decisões e que observem o princípio do contraditório, o que thes confere uma legitimidade derivada do exercício processual, cujas pautas estão contidas nos preceitos constitucionais e nas leis vigentes. 0 exercício da justiça constitucional está, portanto, sujeito à limites.

A função primordial da justiça constitucional é preservar a integridade da Constituição mediante a fixação de critérios objetivos para a compreensão do sentido e alcance de suas disposições. Como afirma Christian Stark, o poder particular de um Tribunal Constitucional reside em sua prerrogativa de interpretação ${ }^{13}$.

\section{Considerações finais}

A supremacia da Constituição, como referência para a construção da racionalidade jurídica contemporânea, exigiu a criação de instrumentos para garantir a efetividade de seus comandos. Essa missão foi atribuída à justiça constitucional.

A principal função da justiça constitucional reside em submeter a validade das leis aos parâmetros da Constituição, com a possibilidade de anular os textos legais incompatíveis com os mandados constitucionais. 0 controle da constitucionalidade das leis é, neste sentido, um exercício hermenêutico. A tarefa encomendada aos juízes constitucionais não é legislar, mas atuar como máximo intérprete da Constituição. Entretanto, o poder conferido à justiça constitucional de invalidar atos do Parlamento reabre a discussão teórica sobre a legitimidade democrática dos órgãos de controle da constitucionalidade das leis.

A tensão produzida pela polarização entre defensores e opositores da justiça constitucional pode ser minimizada por meio de uma redefinição da democracia e das vias de legitimação do poder que se ajustem aos modelos atuais de Estado constitucional. Em outras palavras, a solução para justificar a legitimidade das decisões que invalidam as leis do Parlamento pode estar em um modelo de democracia que não esteja centrado somente nos conceitos de eleição e participação popular.

13 STARK, Christian. Obra citada, p. 490. 
FERRERES COMELLA, Víctor (Dir.). Una defensa del modelo europeo de control de constitucionalidad. $1^{\text {a }}$ edición. Madrid: Marcial Pons, 2011. ISBN 978-84-9768-845-1.

KELSEN, H. La garantia jurisdicional de la Constitución (la justicia constitucional). [Em linha]. (2011) n 15 [consultado em 2020-03-15], pp. 249-300. Disponível na World Wide Web: file:///C:/Users/USER/Documents/Dialnet-LaGarantiaJurisdiccionalDeLaConstitucionLaJusticia-3764308.pdf

LOPERA MESA, Gloria Patricia. La problemática legitimidad de la justicia constitucional. "Anuario Iberoamericano de justicia constitucional". [Em linha]. (2001) nº 5 [Consultado em 2021-04-25], pp. 227-256. Disponível na World Wide Web: https://dialnet.unirioja.es/servlet/articulo?codigo=1976017

QUIROGA, Hugo. ¿Democracia procedimental o democracia sustantiva? La opción por un modelo de integración. [Em linha]. (2000) n³ 3, vol. VI. [Consultado em 2021-05-09], pp. 361-374. Disponível na World Wide Web: https://dialnet.unirioja.es/servlet/articulo?codigo=5848857

STARCK, Christian. La legitimación de la justicia constitucional y el principio democrático. [Em linha]. (2003) n 7 [consultado em 2021-04-19], pp. 479-493. Disponível na World Wide Web: file:///C:/Users/USER/ Documents/Dialnet-LaLegitimacionDeLaJusticiaConstitucionalYElPrincip-761519.pdf. 